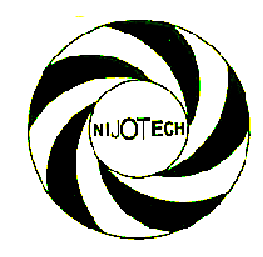

Nigerian Journal of Technology (NIJOTECH)

Vol. 33 No. 4, October 2014, pp. 426 - 435

Copyright@ Faculty of Engineering,

University of Nigeria, Nsukka, ISSN: $1115-8443$

www.nijotech.com

http://dx.doi.org/10.4314/njt.v33i4.2

\title{
HIGH POWER FACTOR HYBRID RECTIFIER
}

\author{
C. I. Odeh \\ DEPARTMENT OF ELECTRICAL ENGINEERING, UNIVERSITY OF NIGERIA, NSUKKA. NIGERIA \\ E-mail address: charles.odeh@unn.edu.ng
}

\begin{abstract}
This paper presents the analysis of a new single-phase hybrid rectifier with high power factor (PF) and low harmonic distortion current. The proposed rectifier structure is composed of an ordinary single-phase diode rectifier with parallel connection of a switched converter. It is outlined that the switched converter is capable of shaping the input line current waveform, assuring high PF and low total harmonic distortion (THD). The power rating of the switched converter is less than $50 \%$ of the total output power; assuring reliability in the proposed hybrid rectifier. A pulse width modulation (PWM) control strategy was developed, imposing quasi-sinusoidal line input current waveform and limiting the switched converter power contribution. It was found that the line input current harmonic spectrum is in accordance with the harmonic limits imposed by IEC61000-3-4. The principle of operation, the mathematical analysis, and simulated results are also presented in the paper.
\end{abstract}

Keywords: Power Factor, Hybrid Rectifiers, Harmonic distortion.

\section{INTRODUCTION}

Due to the remarkable evolution of power electronics, and consequently, the viability of more flexible, compact and efficient new devices, it noted an increase in the number of electrical loads that use some kind of electronic power converter. It is estimated that approximately $50 \%$ of the electricity generated in Brazil, [1], is electronically processed before being actually used. This results in the movement of non-sinusoidal currents in the power circuit. Therefore, there is talk of harmonic distortion of current due to the presence of nonlinear loads (electronic power converters) connected to the mains in alternating current.

Most equipment that process energy electronically operate through an AC power source, but always require an intermediate stage of AC-DC conversion (rectifiers). In this context, due to its wide industrial application, the rectifiers, particularly in Graetz setting, are the most common sources of problems related with the injection of harmonic current components in the AC power system. Thus, supply of load is made from the DC obtained in the rectifier's bridge output (DC bus), [1-5]. The presence of harmonic components of current in the system is largely responsible for: additional losses and heating in electric machines and capacitors, faulty thermo magnetic breakers due to increased internal temperature caused by the variation of RMS value of current, increase in neutral current, increased losses in conductors; errors in conventional instruments for measuring energy consumption, among other problems.

Due to the considerable increase of electronic power processing devices in various segments of industry as well as in those numerous equipment of residential use, it becomes necessary to control and limit this current harmonic content injected into the distribution systems. This can be done through the development of pre-regulator converters for performing not only reduction of harmonic levels of current, but also to correct the input power factor (PF) and control voltage on DC buses.

In this regard, this paper proposes a new hybrid single-phase rectifier capable of reducing the total current harmonic distortion due to the presence of nonlinear loads, correction of PF and high operational reliability. The great advantage provided by hybrid rectifiers is the combination robustness, reliability and simplicity of diode uncontrolled rectifiers with reduced weight and volume provided by switched converters, which operate at high switching frequency. This way, the nominal rating of the hybrid structure can be drastically improved with no 
impairment to the overall efficiency of the rectifier, which cannot be achieved with conventional PWM rectifiers without increasing costs considerably [613]. The proposed single-phase hybrid rectifier consists of an uncontrolled single-phase rectifier (Rect-1), coupled in parallel with single-phase switched converter (Rect-2), as illustrated in Figure 1. It is noteworthy that the main advantages of using hybrid rectifiers at the pre-regulator stage with power factor correction for connecting electronic converters are:

a. Greater overall efficiency of the structure, since the switched converters process reduce portion of active power delivered to the load.

b. Lower cost when compared with conventional switched pre-regulated converters with unitary $\mathrm{PF}$, since the semiconductor devices used in these structures are designed for rated power.

c. Flexibility in meeting the restrictions imposed by the standard IEC610003-4, since the current to be imposed on the AC mains supply can take different forms depending on the desired THD.

d. Simple, inexpensive and efficient control technique.

As illustrated in figure 2, the drawn current from the network ( $i_{\text {in }}$ ) will be the composition of that required by the uncontrolled rectifier $\left(\mathrm{i}_{\mathrm{L} 1}\right)$ and the portion of the switched converter $\left(i_{L_{2}}\right)$. The waveform of current $i_{\text {L2 }}$ will be directly responsible for the final characteristic of the waveform of the AC power supply.

Aiming at validating the overall front-end rectifier structure, simulation results are given to verify the proposed methodology accuracy at providing DC link from power electronics converters connection at high input factor and low harmonic distortion of input current.

\section{THE CONFIGURATION AND OPERATIONAL PRINCIPLE OF THE PROPOSED HYBRID RECTIFIER.}

As shown in Figure 1, the proposed single-phase frontend hybrid rectifier is composed by the combination of two rectifier groups. The first one is a single-phase diode rectifier operating in discontinuous current mode (DCM), named Rect-1; and the second is a switched converter, named Rect-2, operating with imposed input current in order to obtain nearly sinusoidal AC line current. The proposed hybrid rectifier power circuit is shown in Figure 2.

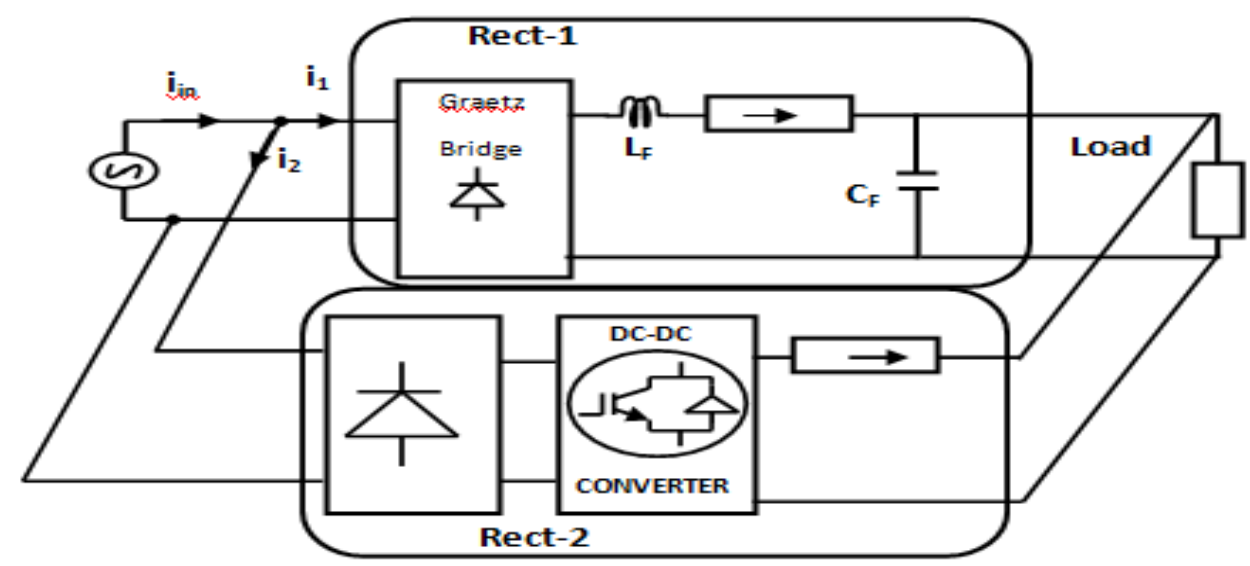

Figure 1: Composition of the proposed hybrid rectifier.

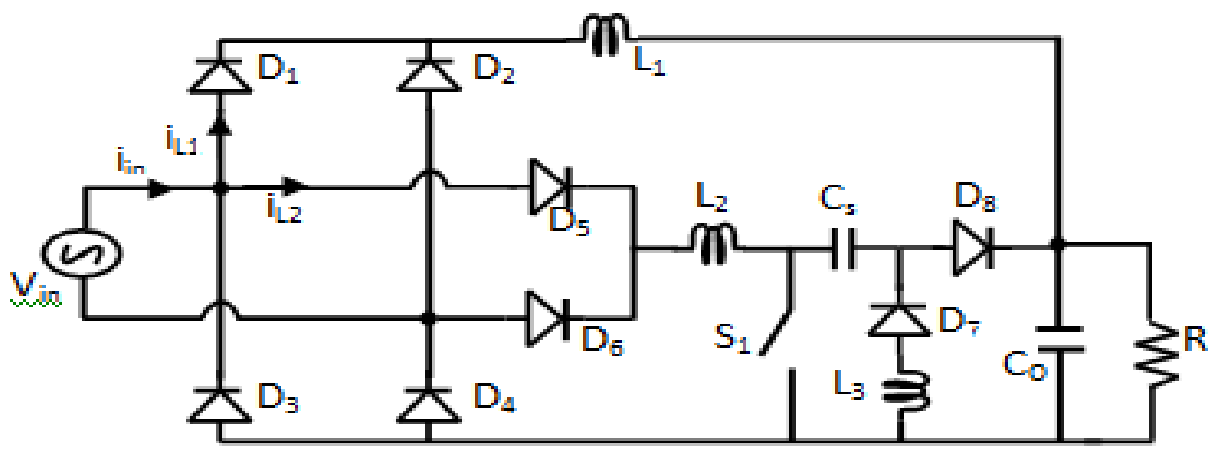

Figure 2: Power circuit of the proposed hybrid rectifier. 
One can observe that the AC line current is a result of the summation of currents $i_{L 1}$ and $i_{L 2}\left(i_{L 1}+i_{L 2}\right)$, provided that current $i_{L 1}$ is the classical input current of single-phase diode rectifier operating in DCM and $\mathrm{i}_{\mathrm{L} 2}$ is the input current of the switched converter imposed by a suitable control strategy following the desired sinusoidal reference, as shown in Figure 3 and described as follows:

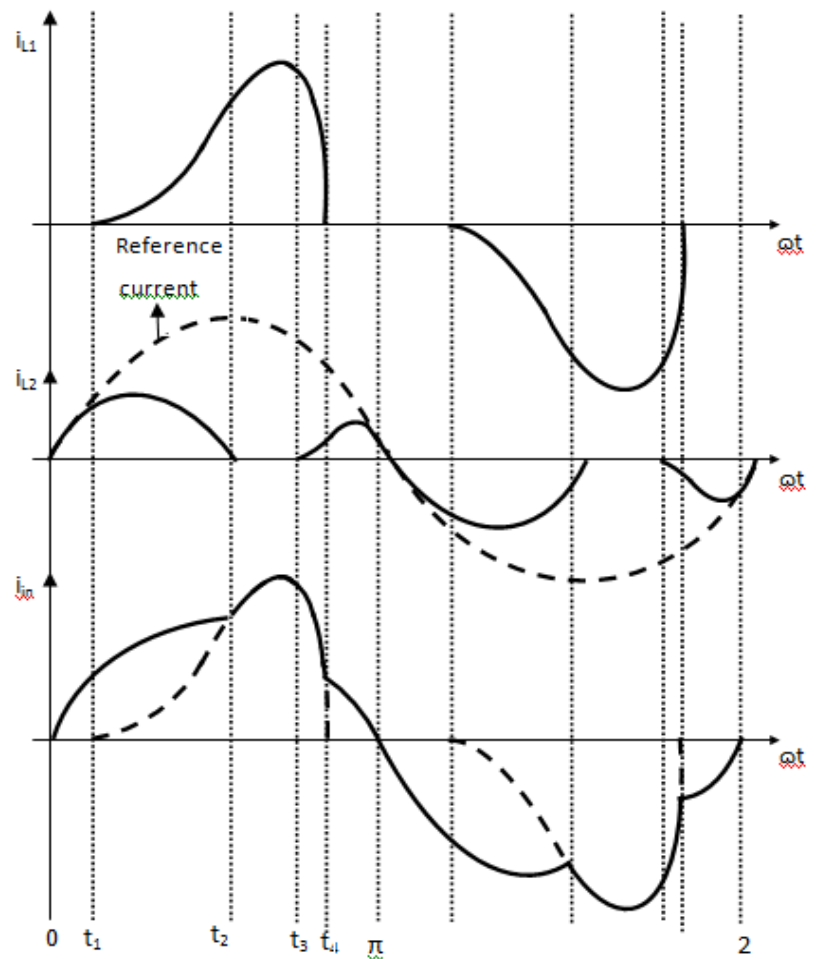

Figure 3: Individual rectifier current waveforms and the synthesized input current of the proposed hybrid rectifier.

From 0 to $t_{1}$ : the diode bridge rectifier (Rect-1) is blocked, i.e. the output voltage is higher than the input. Therefore, the current imposition through inductor $\mathrm{L}_{2}$ starts, following the sinusoidal reference. During this period, the diode rectifier (Rect-1) is out of operation.

From $t_{1}$ to $t_{2}$ : the input voltage is higher than the output voltage, hence the diode bridge rectifier starts conducting and current $\mathrm{i}_{\mathrm{L} 1}$ starts increasing due to $\mathrm{V}_{\text {in }}$ . In this instant, Rect-1 starts providing energy to the load and therefore, the switched converter (Rect-2) power contribution starts decreasing, represented by the current $i_{\mathrm{L} 2}$ decrease which follows the imposed sinusoidal reference current.

From $t_{2}$ to $t_{3}$ : only Rect- 1 provides energy to the load. During this period, the $\mathrm{AC}$ input current is equal to the current flowing through the inductor $\mathrm{L}_{1}$ of Rect- 1 .
From $t_{3}$ to $t_{4}$ : the switched converter starts operating again following the sinusoidal imposed reference. Current $i_{L 1}$ reaches zero in $t_{4}$ once output voltage gets higher than the input voltage, $V_{\text {in }}$; hence, the diode rectifier is out of operation.

From $t_{4}$ to $\pi$ : only the switched converter provides energy to the load, since the diode rectifier is blocked by the output voltage. Thus, during this period of time, the input line current is equal to the switched converter input current.

Finally, it should be noted that the switched converter imposed current waveform is responsible for defining the final AC input line current waveform; providing therefore a considerable reduction of its harmonic components. It is important to outline that despite the unusual waveform, the frequency spectrum of the input current is in accordance with harmonic content restrictions imposed by international standard IEC61000-3-4, as demonstrated in the theoretical and simulations results herein.

\section{ANALYTICAL MODELING OF THE HYBRID RECTIFIER}

In order to employ the concept of hybrid rectifiers presented in $[9,10]$ in single-phase systems, it is necessary to implement an ordinary diode rectifier in DCM. The DCM operation can be assured when the inductor and capacitor input filters are very small and large, respectively. In the limit as the inductor value goes to zero and the capacitor value goes to infinite, the $\mathrm{AC}$ input current approximates to an impulse function, as shown in Figure 4.

As one can observe, the AC input current is discontinuous once the diode rectifier bridge conducts for less than one-half of the AC line period; or during a time interval less than $180^{\circ}$.

\subsection{Analysis of single-phase diode rectifier in DCM.}

The analysis of diode rectifier operating in DCM can be divided into two cases which correspond to the inductor current waveforms shown in Figure 4, [14, 15]. In both cases, conduction of the diode bridge rectifier begins when the AC input voltage, $V_{\text {in }}$, is higher than the output voltage across the filter capacitor, $\mathrm{V}_{\mathrm{co}}$, illustrated in Figure 5. 

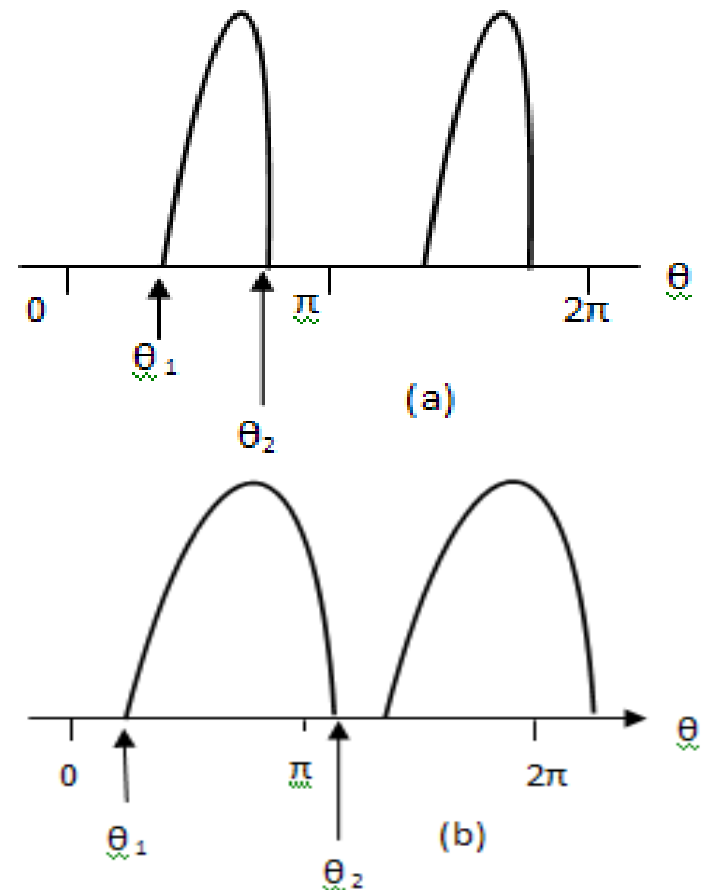

Figure 4: Inductor current waveform of a diode bridge rectifier operating in DCM.

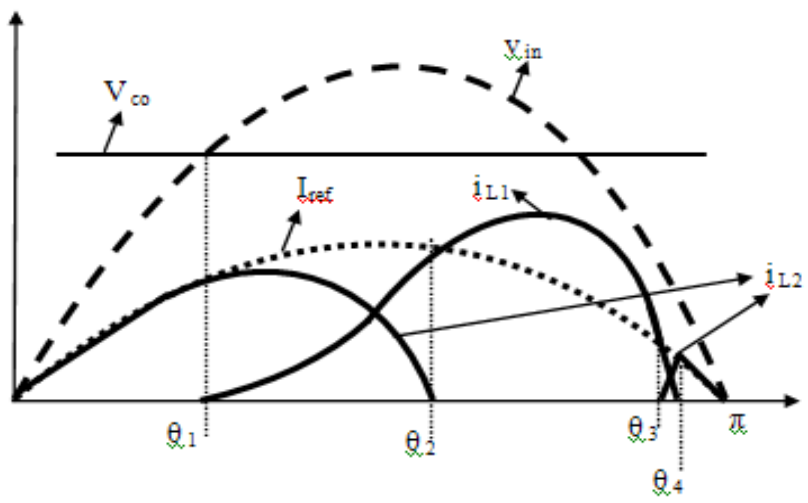

Figure 5: Inductor current waveform of a diode bridge rectifier operating in DCM.

The angle $\theta_{1}$ is defined as the value of $\theta$ at this instant, leading to the following relation:

$$
\frac{V_{c o}}{V_{\text {in }}}=\sin \theta_{1}
$$

The angle $\theta_{2}$ is defined as the value of $\theta$ at the instant the inductor current, $i_{\text {L2 }}$ reaches zero. The case 1 , illustrated in Figure 4(a) refers to the operational condition where the inductor current returns to zero at the same half cycle of the AC line voltage; thus, $\theta_{2}$ $<\pi$. Case 2, illustrated in Figure 4(b), occurs when the inductor current extends to the next half cycle of the $\mathrm{AC}$ line voltage.; hence, $\theta_{2}>\pi$. Therefore, for case 1 , the inductor current can be expressed as

$$
i_{d}(\theta)=\frac{V_{i n}}{\omega L}\left[\cos \theta_{1}-\cos \theta-\left(\theta-\theta_{1}\right) \sin \theta_{1}\right]
$$

The angle $\theta_{2}$ can be obtained from

$$
\left[\cos \theta_{1}-\cos \theta_{2}-\left(\theta_{2}-\theta_{1}\right) \sin \theta_{1}\right]=0
$$

$\theta_{2}$ can be evaluated by numerically solving the transcendental equation presented in (3). Thus, one can obtain the value of $\theta_{2}$ that satisfies (3) and at same time, is less than $\pi$.

\subsection{Analysis of the parallel switched converter.}

Boost converters have been traditionally used as front end wave shaping systems. But, in order to be applied as a parallel path in the proposed singlephase hybrid rectifier, non-isolated Boost converters are technically impracticable. Since during the period of time when the input line voltage is higher than the DC output voltage, the Boost current continues increasing, even when the switch is open. It should be emphasized that for isolated Boost converters fed through the single-phase transformer, there is a galvanic isolation and, as a result, such structure can be employed; but with the obvious drawbacks of requiring extra magnetic devices; i.e higher volume, weight and cost.

On the other hand, SEPIC converters behave naturally as an input current source; allowing for the waveform of the input current be imposed with a suitable control strategy. In contrast to the Boost converter behavior, when the switch of the SEPIC converter is opened, the series capacitor assures, at any operating condition, the decrease of the current flow through the input inductor. Thus, the imposition of the input current does not strongly depend on the level of the output voltage (DC link voltage), as depicted in Figure 5.

Therefore, the switched converter associated in parallel connection with diode rectifier must operate as an input current source in order to compose the input line current, assuring high power factor and low THD.

\subsection{Analysis of the proposed single-phase hybrid rectifier.}

Analytically, the principle of operation of the proposed structure can be described in five different stages taking into account a half-cycle of $50 \mathrm{~Hz}$, as portrayed in Figure 5. In this figure, one can observe the theoretical waveforms of the output voltage $\left(\mathrm{V}_{\mathrm{co}}\right)$, the input voltage, $\left(V_{\text {in }}\right)$, the SEPIC input inductor current, (i $\left.i_{L 2}\right)$, the reference current, $\left(I_{\text {ref }}\right)$, and diode rectifier input current, ( $\left.i_{L 1}\right)$ as a function of $\theta$. From the analysis of Figure 5, it is possible to select the power semiconductor switch and the magnetic elements through determination of current $i_{L 1}$ and $i_{L 2}$ equations. 
In the intervals: 0 to $\theta_{1}$ and $\theta_{4}$ to $\pi$, only SEPIC converter provides power to the load, therefore:

$$
C_{o} \frac{d V_{c o}}{d t}=I_{D 9}-\frac{V_{c o}}{R}
$$

During the intervals: $\theta_{1}$ to $\theta_{2}$ and $\theta_{3}$ to $\theta_{4}$, both SEPIC converter and diode rectifier provide power to the load, therefore:

$$
C_{o} \frac{d V_{c o}}{d t}=I_{L 1}+I_{D 9}-\frac{V_{c o}}{R}
$$

In the interval $\theta_{2}$ to $\theta_{3}$, only the diode rectifier provides power to the load, therefore:

$$
C_{o} \frac{d V_{c o}}{d t}=I_{L 1}-\frac{V_{c o}}{R}
$$

\section{DESIGN GUIDELINE FOR DETERMINATION OF EACH RECTIFIER GROUP POWER CONTRIBUTION.}

As stated in section 3, the input inductor of Rect-1 must be designed to operate in DCM. The proposed design guideline provides a precise way of determining the optimum value of the diode rectifier input inductor and tackles the input line current composition at low THD with maximum diode rectifier output power contribution. In this context, two considerations must be outlined: Firstly, the higher is the conduction time diode rectifier $\left(\theta_{1}\right.$ to $\theta_{4}$ in Figure 5), the higher is its power contribution. Secondly, the switched converter input current must follow a sinusoidal reference and its power contribution must be enough to achieve an input line current in accordance with IEC61000-3-4.

\subsection{Project assumptions}

In steady state and taking into account a lossless system, the input active power is equal to the active output power in the load. Therefore,

$$
\frac{V_{\text {in }(\text { peak })}}{\sqrt{2}}\left(\frac{1}{\pi}\right) \int_{0}^{\pi} i_{\text {in }}^{2}(\theta) d \theta=\frac{V_{\text {co(avg })}^{2}}{\mathrm{R}}
$$

where: $V_{\text {in(peak) }}$ is the peak value of the input voltage, $\mathrm{V}_{\mathrm{co}(\mathrm{avg})}$ is the average value of the output voltage, $\mathrm{R}$ is the load resistance and $i_{\text {in }}(\theta)$ is the input current. The diode rectifier input current is given by (2) and the SEPIC converter input current is given by

$$
i_{L 2}(\theta)=I_{r e f} \sin \theta
$$

where $I_{\text {ref }}$ is the peak value of the sinusoidal reference current.

\subsection{Power contribution of each rectifier group}

Considering an infinite output capacitor $\left(\mathrm{C}_{0}\right)$, the output voltage is constant and equal to $\mathrm{V}_{\mathrm{co}}$, therefore the load power is

$$
P_{o}=\frac{V_{c o}^{2}}{\mathrm{R}}
$$

The diode rectifier and SEPIC converter power contributions are given by (9) and (10), respectively.

$$
\begin{aligned}
P_{\text {Rect }-1} & =k_{p} \frac{V_{c o}^{2}}{R} \\
P_{\text {Rect-2 }} & =\left(1-k_{p}\right) \frac{V_{c o}^{2}}{R}
\end{aligned}
$$

where $k_{p}$ is the ratio of diode rectifier power contribution in relation to the total output power.

\subsection{Angles $\theta_{1}$ and $\theta_{4}$; and inductance $L_{1}$}

As presented in (1), the initial conduction angle of current $\mathrm{i}_{\mathrm{L} 1 \mathrm{can}}$ be found from (12)

$$
\sin \theta_{1}=\frac{V_{c o}}{V_{\text {in }(\text { peak })}}
$$

In the analysis presented in section 3 , current $\mathrm{i}_{\mathrm{L} 1}$ is defined by

$$
\begin{aligned}
i_{L 1}(\theta)=\mathrm{F}(\theta)= & \frac{V_{\text {in }(\text { peak })}}{\omega L_{1}}\left[\cos \theta_{1}-\cos \theta-(\theta\right. \\
& \left.\left.-\theta_{1}\right) \sin \theta_{1}\right]
\end{aligned}
$$

Since current $i_{L 1}$ is a function of angle $\theta$, for each initial conduction angle $\theta_{1}$, a final angle $\theta_{4}$ is defined, as well as a maximum value for function $F(\theta)$. Thus making $\theta_{4} \leq \pi$, (Figure 5 ), and solving (3) through an iterative way, a minimum initial conduction angle of $46.43^{\circ}\left(\theta_{1(\min )}\right)$ is found. In this limit situation, where $\theta_{4}=\pi$, current $i_{L 1}$ maximum value can be found by equating the derivative of $i_{\mathrm{L} 1}(\theta)$ to zero. Hence,

$$
I_{L 1(\max )}=\frac{2 V_{\text {in }(\text { peak })}}{\omega L_{1}}\left[\cos \theta_{1}-\left(\frac{\pi}{2}-\theta_{1}\right) \sin \theta_{1}\right]
$$

One can associate this limit situation to the maximum current contribution of Rect-1. Moreover, the diode rectifier power contribution can also be found from (15).

$$
P_{R e c t-1}=V_{c o} I_{L 1(a v g)}=k_{p} \frac{V_{c o}^{2}}{R}
$$

Substituting $\theta_{1}=46.43^{\circ}$ and $\theta_{4}=180^{\circ}$ in (14), the maximum average value of current $\mathrm{i}_{\mathrm{L} 1}$ is

$$
I_{L 1(\text { avg-max })}=0.1154\left(\frac{V_{\text {in (peak })}}{\omega L_{1}}\right)
$$

Therefore, substituting (16) into (15), the maximum power contribution of Rect- 1 is

$$
I_{L 1(\text { avg-max })}=0.1154\left(\frac{V_{\text {in(peak })}}{V_{c o}}\right)\left(\frac{R}{\pi \omega L_{1}}\right)
$$

Finally, for a given load condition and defining the maximum power contribution of Rect- 1 and the desired output voltage, the input filter inductor value of Rect-1 can be found from (17). 


\subsection{Angles $\theta_{2}$ and $\theta_{3}$ and the reference current to be imposed in inductor $\mathrm{L}_{2}$}

For obtaining low THD at the input, the input line current must follow a sinusoidal reference current. Besides, aiming at the limitation of the SEPIC converter power contribution, the peak value of the SEPIC converter input inductor current ( $i_{L 2}$ ) must be less than the peak value of current $i_{L 1}$. Thus, one can find the reference current value as well as the values of angles $\theta_{2}$ and $\theta_{3}$ as a function of the parameter $K$, which represents the relation between the peak value of the reference current and the peak value of current $\mathrm{i}_{\mathrm{L} 1}$.

$$
K=\frac{I_{\text {ref }}}{I_{L_{1(\text { peak })}}}
$$

Substituting (14) in (18), the reference current is given as

$$
I_{\text {ref }}=\frac{2 K V_{\text {in }(\text { peak })}}{\omega L_{1}}\left[\cos \theta_{1}-\left(\frac{\pi}{2}-\theta_{1}\right) \sin \theta_{1}\right](19)
$$

From Figure 5, one can see that the angles $\theta_{2}$ and $\theta_{3}$ correspond to the intersection of $\mathrm{i}_{\mathrm{L} 1}(\theta)$ and $\mathrm{I}_{\mathrm{ref}}(\theta)$ curves. Therefore,

$$
\begin{gathered}
2 K\left[\cos \theta_{1}-\left(\frac{\pi}{2}-\theta_{1}\right) \sin \theta_{1}\right] \\
=\left[\cos \theta_{1}-\cos \theta_{2}\right. \\
\left.-\left(\theta_{2}-\theta_{1}\right) \sin \theta_{1}\right] \\
2 K\left[\cos \theta_{1}-\left(\frac{\pi}{2}-\theta_{1}\right) \sin \theta_{1}\right] \\
=\left[\cos \theta_{1}-\cos \theta_{3}\right. \\
\left.-\left(\theta_{3}-\theta_{1}\right) \sin \theta_{1}\right]
\end{gathered}
$$

Equations (20) and (21) can be solved to obtain the values of $\theta_{2}$ and $\theta_{3}$.

Another condition that must be satisfied by $\mathrm{K}, \theta_{2}$ and $\theta_{3}$ in order to obtain the SEPIC converter power contribution is that the average value of the instantaneous input power must be equal to the active power delivered to the load. It means that equation (22) holds.

Hence, one can define $K=0$ and $\theta_{2}=\theta_{1}$ initially. The convergence of (20) is verified and $\theta_{2}$ is increased until both terms in (20) are equal for the same value of $K$. Since (20) is satisfied, a partial value of $\theta_{2}$ is found. For obtaining $\theta_{3}$, one can define $\theta_{3}=\theta_{2}$ partially. For the same $\mathrm{K}$ used to obtain $\theta_{2}$ partial, $\theta_{3}$ is increased until (21) is satisfied and a partial value of $\theta_{3}$ is found. Finally, one can verify if (22) is also satisfied; and if not true, $\mathrm{K}$ is increased and new values of $\theta_{2}$ and $\theta_{3}$ are found until (20), (21) and (22) are satisfied simultaneously. Since the final values of $K, \theta_{2}$ and $\theta_{3}$ are found, for a given value of $K$, one can obtain the reference current peak value, $\mathrm{I}_{\text {ref, }}$ from (18).

\section{CONTROL STRATEGY}

The applied PWM control technique is based on the imposition of the input line current at low THD in order to obtain high input factor. The DC link voltage is not controlled, so its value depends on the peak value of the input line voltage being defined in (1). Focusing on this subject, the proposed control technique tackles at first place the imposition of a quasi-sinusoidal input line current which is in conformity with IEC61000-3-4 standard. The second target goes towards the limitation of the switched converter power contribution in order to assure that the SEPIC converter will never assume the total power. Otherwise, the output becomes higher than the input and the diode rectifier will be disabled leading to the destruction of the SEPIC converter. Thus, in order to achieve the second target, the peak value of the imposed current, i.e. the SEPIC converter input current, must be kept less than the peak value of the diode rectifier input current. The schematic diagram of the proposed control circuit is shown in Figure 6.

In order to impose quasi-sinusoidal waveform at the input of the proposed front-end converter, a sinusoidal reference signal must be obtained. High input power factor can be assured if the imposed current waveform is in phase with the input line voltage. Therefore, a sample of the input line voltage $\left(V_{\text {in }}\right)$ must be rectified and taken to a multiplier circuit as depicted in Figure 6.

At this point, it is important to emphasize that different load conditions cause variations on the DC link voltage and in the values of $\theta_{1}$ through $\theta_{4}$, since they strongly depend on the DC link voltage level. In this way, the waveform and the average value of the input inductor filter current $\left(i_{L 1}\right)$ of diode rectifier also vary; and hence the final waveform of the input line current $\left(i_{i n}\right)$. Due to $i_{\text {in }}$ variations, the power contribution of Rect- 1 also varies.

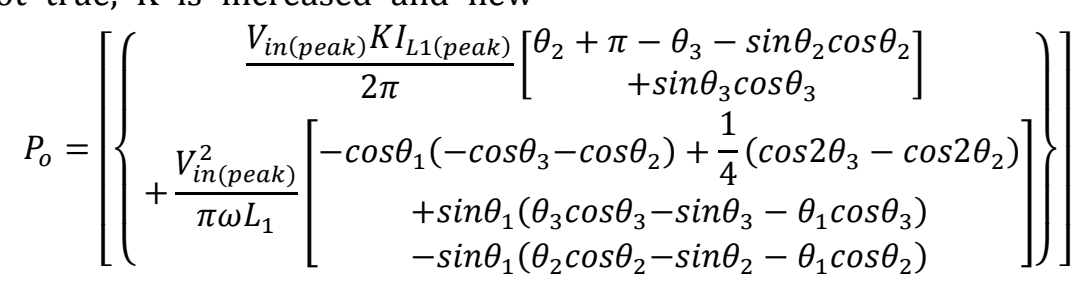




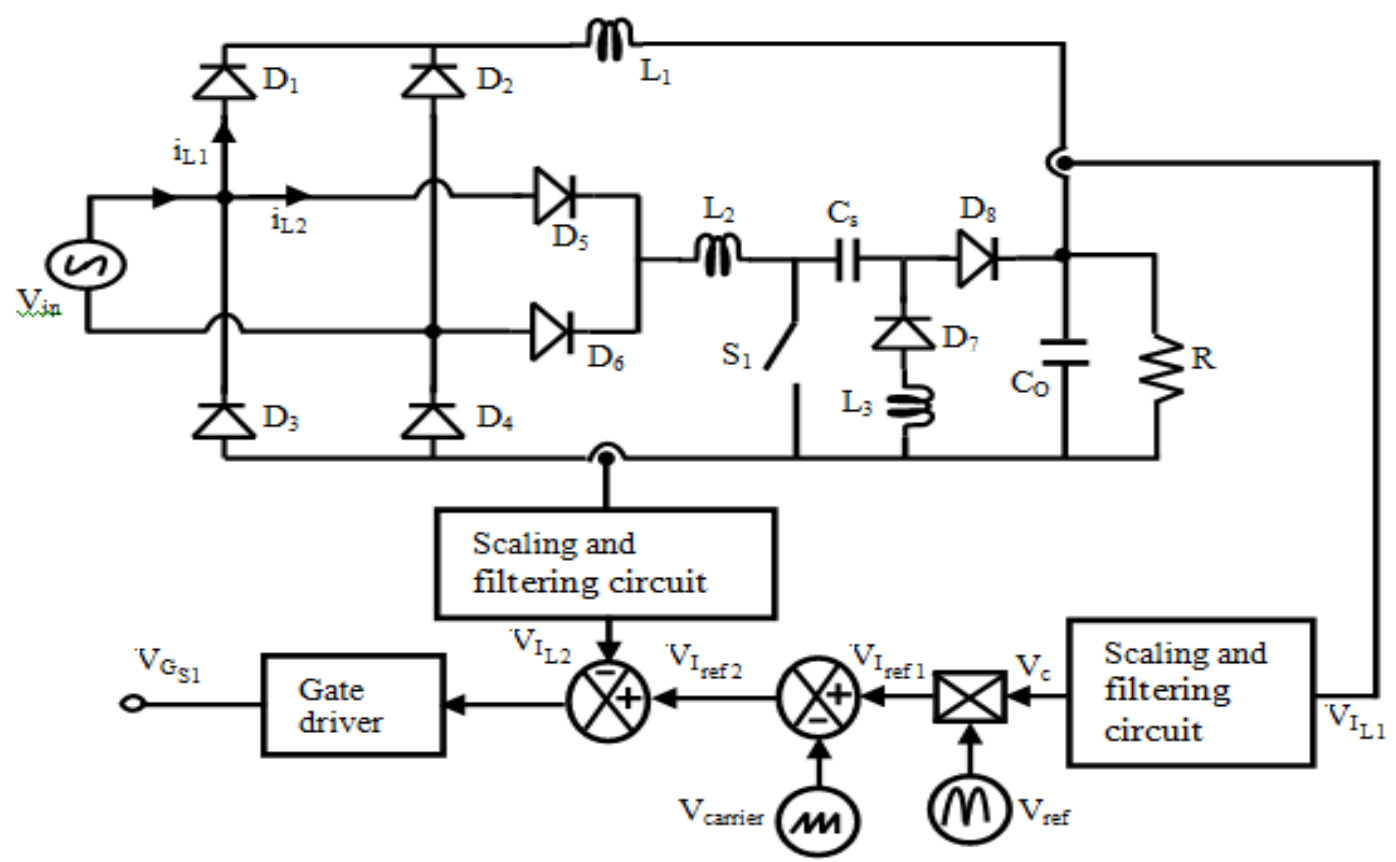

Figure 6: Closed loop control scheme for the proposed hybrid rectifier.

Therefore, aiming at implementing a closed-loop control strategy capable of assuring the accurate input line current composition and the desired SEPIC converter power contribution, current $i_{\text {in }}$ must be sensed and filtered in order to obtain a control voltage $V_{c}$ which is used to update the reference current signal for different load conditions.

As can be seen in Figure 6, at the output of the multiplier circuit one can obtain a reference signal proportional to the applied load $V_{\text {ref-1. }}$. In order to generate a PWM reference signal, a carrier signal (sawtooth voltage waveform, at $20 \mathrm{kHz}$ ) is compared with $\mathrm{V}_{\text {ref-1. }}$. This comparison results in a PWM reference signal $V_{\text {ref-2. }}$ The suitable gain setup of the current sensor circuit assures that the reference current signal and hence the peak value of the SEPIC converter imposed current, $i_{\mathrm{L} 2}$ is always smaller than the peak value of current $i_{L 1}$. Therefore, the desired input line current waveform can be imposed and, at the same time, the SEPIC converter power contribution is also limited to a desired value; since the maximum amplitude of the reference current signal is adjusted at rated power.

Finally, the PWM reference signal, $V_{\text {ref-2, }}$ must be compared with the current flowing through the inductor $\mathrm{L}_{2}$ of the SEPIC converter to generate a high frequency gate drive signal for switch $S_{1}$. Hence, the current through the inductor $\mathrm{L}_{2}$ will follow the imposed reference through a simple PWM control strategy $[16,17]$.

\section{SIMULATION RESULTS}

To verify and demonstrate the operational effectiveness of the proposed single-phase, high power factor hybrid rectifier, the closed-loop circuit of Figure 6 was simulated. The circuit parameters of the simulation are summarized in Table 1.

Table 1: Simulation parameters

\begin{tabular}{|l|c|}
\hline \multicolumn{2}{|c|}{ Design specifications } \\
\hline 1 & Average output voltage, $\mathrm{V}_{\mathrm{o}(\text { avg })}=540 \mathrm{~V}$ \\
\hline 2 & Active output power, $\mathrm{P}_{\mathrm{o}}=10 \mathrm{~kW}$ \\
\hline 3 & Input voltage, $\mathrm{V}_{\text {in }(\mathrm{rms})}=480 \mathrm{~V}$ \\
\hline 4 & Switching frequency $=20 \mathrm{kHz}$ \\
\hline & Circuit parameter values \\
\hline 1 & $\mathrm{~L}_{1}=9.5 \mathrm{mH}$ \\
\hline 2 & $\mathrm{~L}_{2}=\mathrm{L}_{3}=800 \mu \mathrm{H}$ \\
\hline 3 & $\mathrm{C}_{\mathrm{o}}=600 \mu \mathrm{F}$ \\
\hline 4 & $\mathrm{C}_{\mathrm{s}}=10 \mu \mathrm{F}$ \\
\hline
\end{tabular}

For a given value of $K$, the input current waveforms of Rect- 1 and Rect-2 are displayed in Figure 7. Shown in Figure 8 (a) are $\mathrm{i}_{\mathrm{L} 1}, \mathrm{i}_{\mathrm{L} 2}$ and $\mathrm{I}_{\mathrm{ref}}$; where the tracking of $\mathrm{i}_{\text {ref }}$ by $\mathrm{I}_{\mathrm{L} 2}$ is clearly depicted. Sum of $\mathrm{i}_{\mathrm{L} 1}$ and $\mathrm{i}_{\mathrm{L} 2}$ gives the input line current waveform portrayed in Figure 8(b); wherein the input voltage waveform is also plotted. The output voltage of the hybrid rectifier is shown in Figure 9. For the achieved input current waveform, Fourier analysis is performed and the achieved frequency spectrum is compared with the harmonic content restrictions imposed by IEC $61000-3-4$ as shown in Figure 10. 
For different values of $\mathrm{K}$, the final THD is found and the results are presented in Figure 11. Furthermore, Rect- 1 and Rect- 2 power contributions as a function of $\mathrm{K}$ are also portrayed in Figure 10. From the analysis of Figure 11 , one can observe that with $40 \%$ of power contribution, the switched converter operates with an input inductor current that composes the input line current waveform with the desired harmonic spectrum, which is in accordance with IEC 61000-3-4.

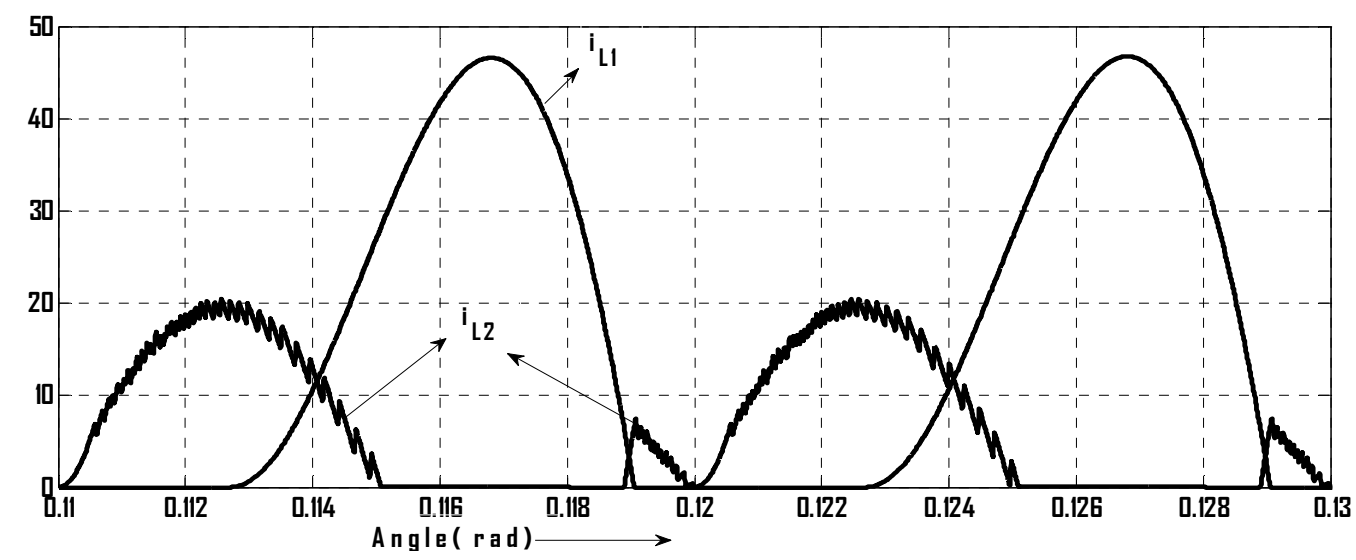

Figure 7 : Simulated input inductor current waveforms of the proposed hybrid rectifier.

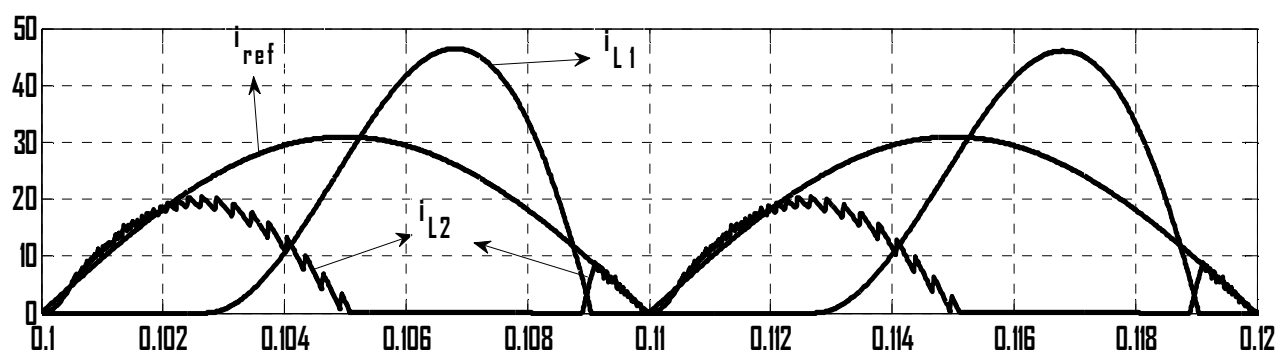

(a) $\rightarrow$ Angle (rad)

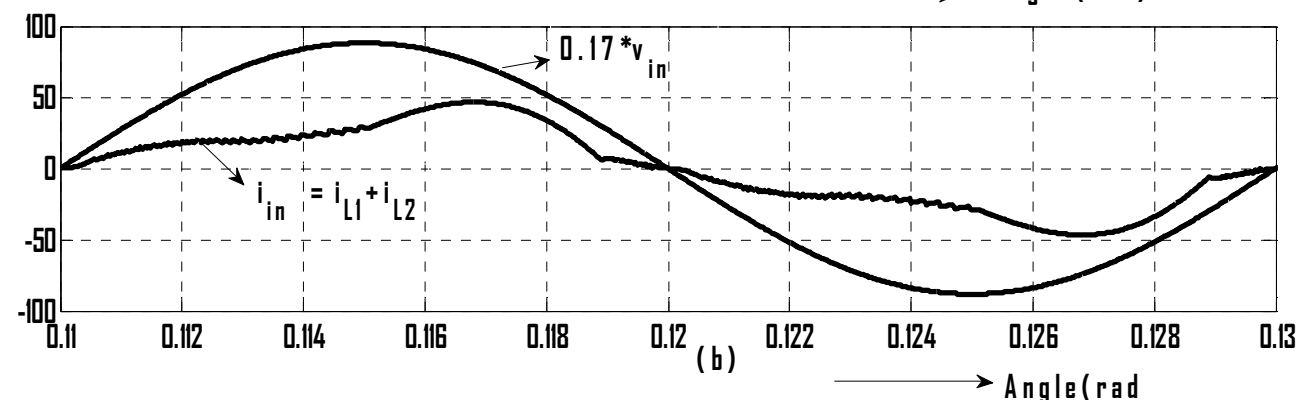

Figure 8 : Simulated waveforms of the proposed hybrid rectifier: (a) Reference current signal, $i_{L 1}$ and $i_{L 2}$; (b) Input current and voltage waveforms.

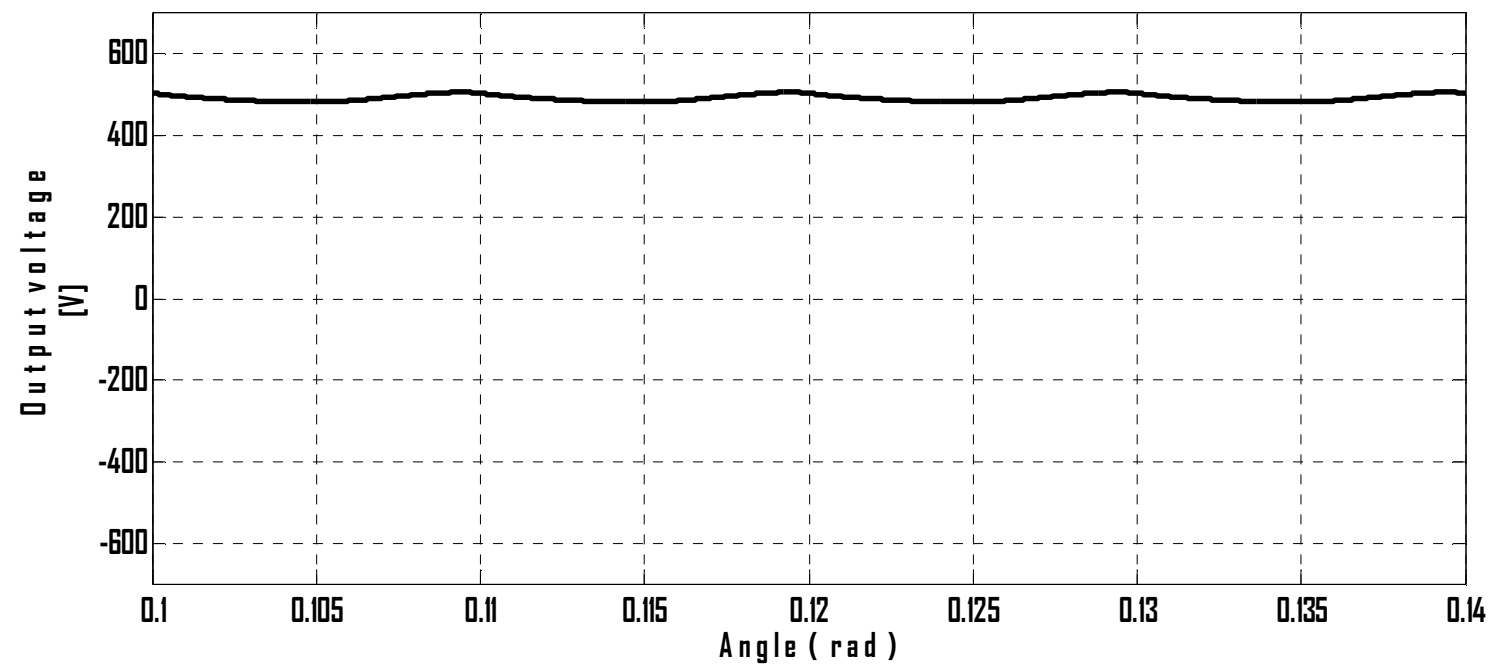

Figure 9 : Simulated waveform of the output voltage of the proposed hybrid rectifier. 


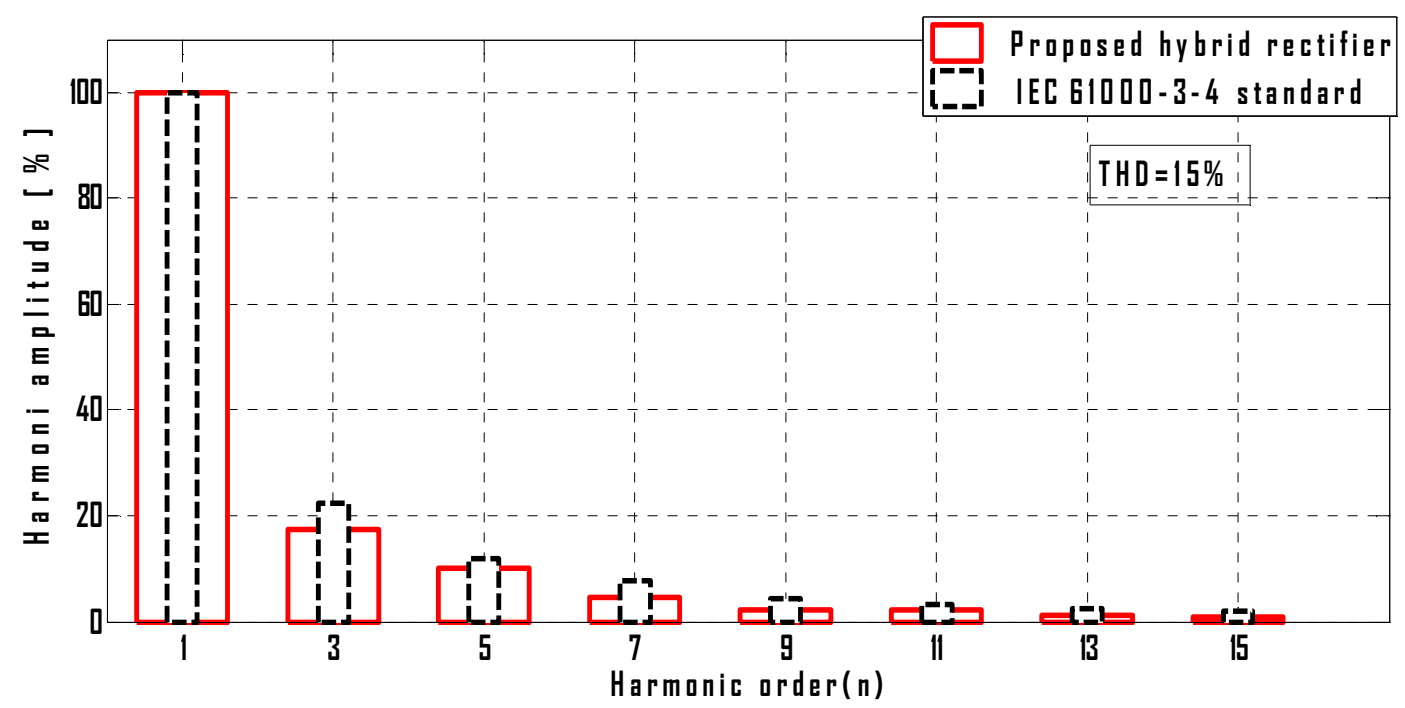

Figure 10: Comparison of the harmonic profile of the proposed hybrid rectifier and the harmonic content restrictions imposed by IEC 61000-3-4.
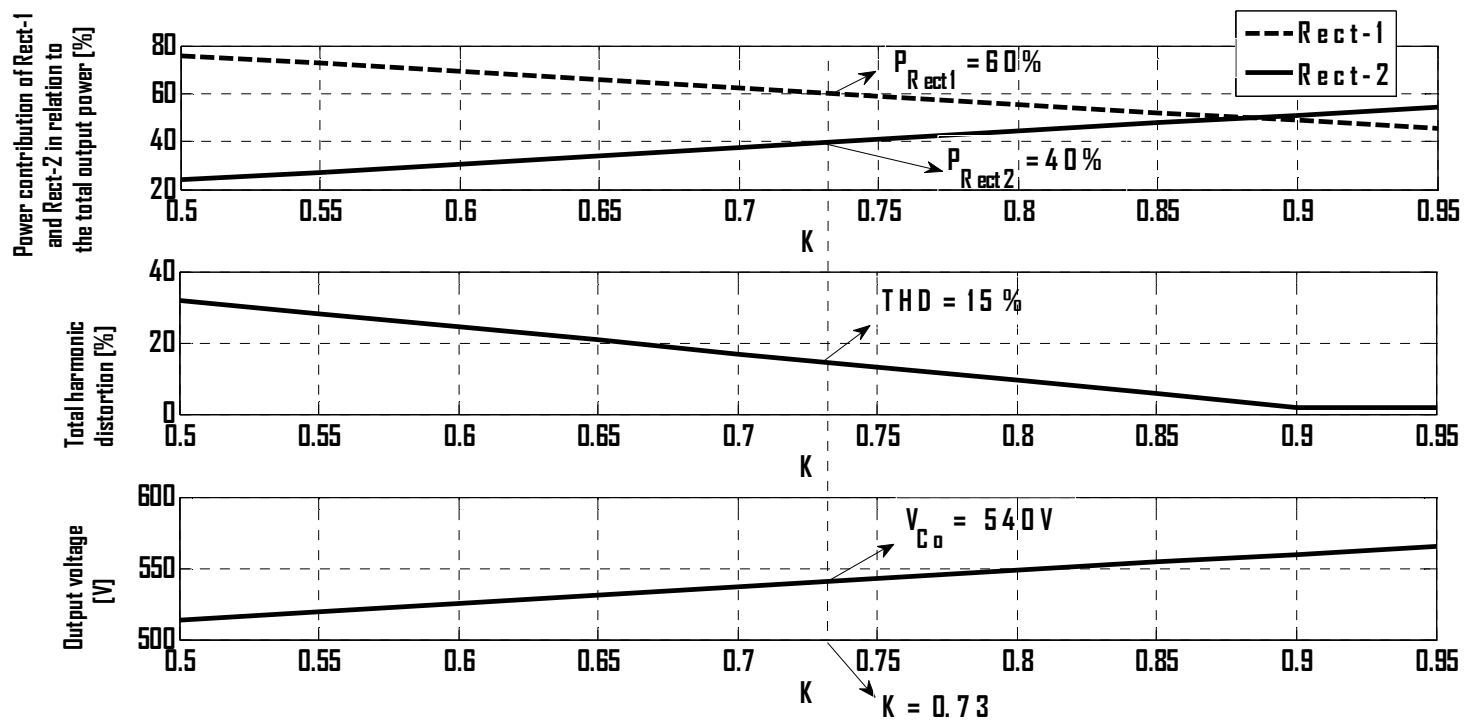

Figure 11 : Plot of power contributions of Rect-1 and Rect-2; THD; and Output voltage as a function of K

\section{CONCLUSIONS}

This paper presented the developmental analysis of a novel high power factor and low harmonic distortion single-phase, hybrid rectifier suitable for high power applications. The proposed structure is composed by an ordinary single-phase diode rectifier combined with parallel connected switched converter. It was demonstrated that the switched converter is capable of composing the AC input line current waveform, providing high power factor and low harmonic distortion. However, the switched converter power contribution is limited to $40 \%$ maximum of the load power, assuring robustness and reliability for the proposed front end structure. A simple PWM control technique was implemented in order to impose an input line current waveform in accordance with the harmonic content restrictions imposed by IEC 61000 -
3-4; and also to limit the switched converter power contribution. Since, $60 \%$ of the total output power is processed by an ordinary single-phase diode rectifier, a robust and high efficient single-phase, high power factor hybrid rectifier structure could be achieved.

\section{REFERENCES}

[1] N. Oishi, H. Okada, K. Ishizaka, R. Itoh, "Single-phase step-up/step-down rectifier with improved supply current waveform", IEE Proc. Electrical Power Applications, vol. 144, no. 1, pp. 6-12, Jan. 1997.

[2] J.J. Shieh, "Sepic derived three-phase switching mode rectifier with sinusoidal input current ", IEE Proc. Electrical Power Applications, vol. 147, no. 4, pp. 286-294, Jul. 2000.

[3] B.R. Lin, D. J. Chen, "Single-phase neutral-point diode clamped rectifier with high input power factor", IEE 
Proc. Electrical Power Applications, vol. 149, no. 1, pp. 31-38, Jan. 2002.

[4] H. Plesko, J. Biela, J. Luomi, J. W. Kolar, "Novel concepts for Integrating the Electric drive and Auxiliary DC-DC Converter for Hybrid Vehicles ", IEEE Transactions on Power Electronics vol. 23, no. 6, pp. 3025-3034, Nov. 2008.

[5] H. S. Athab, D. D. C. Lu, "Simple controller for singlephase power factor correction rectifier", IET Power Electron. vol. 3, Iss. 4, pp. 590-600, Nov. 2010.

[6] D. A. Paice, "Power Electronic Converter Harmonic Multipulse Methods for Clean Power", Willey, 2001 ISBN 0-7803-5394-3.

[7] B. Sing, B. N. Sing, A Chandra et al., "A review of three-phase improved power quality AC-DC converters ", in IEEE Transactions on Industrial Electronics vol. 51, no. 3, pp. 641-660, Nov. 2004.

[8] K. Mino, G. Gong, J. W. Kolar, "Novel hybrid12-pulse boost-type rectifier with controlled output voltage ", in IEEE Transactions on Aerospace and Electonic system vol. 41, no. 3, pp. 1008-1018, Jul. 2005.

[9] L. C. G. Freitas, M. G. Simoes, C. A. Canesin, L. C. de Freitas, "Novel programmable pfc base hybrid rectifier for ultra clean power application ", IEEE Transactions on Power Electronics vol. 21, no. 4, pp. 956-966, Jul. 2006.

[10] L. C. G. Freitas, M. G. Simoes, C. A. Canesin, L. C. de Freitas , "Performance evaluation of a novel hybrid multipulse rectifier for utility interface of Power Electronic converters ultra clean power application
", IEEE Transactions on Industrial Electronics vol. 54, no. 6, pp. 3030-3041, Dec. 2007.

[11] A. N. Tiwari, P. Agawal and S. P. Srivastava , "Modified hysteresis controlled PWM rectifier", IEE Proc. Electric Power Appl. vol. 150, no. 4, Jul. 2003.

[12] M. E. Villablanca, "Method and apparatus to reduce current distortion in line commutated rectifiers ", in IET Power Electron vol. 2, Iss. 3, pp. 287-296, 2009.

[13] R. Kalpana, G. Bhuvaneswari, B. Sigh, S. Singh , "Harmonic mitigator based on 12-pulse ac-dc converter for switched mode power supply ", IET Power Electron. vol. 3, Iss. 6, pp. 947-964, 2010.

[14] S. Freeland, "I. Unified Analysis of Converters with Resonant Switches, II. Input-Current Shaping for Single-phaseAc-Dc Power Converters ", in Ph.D Thesis- Califonia Institute of Technology, Capitulo 12, 1988.

[15] R. W. Erickson and D. Maksimovic , "Fundamentals of Power Electronics", Springer Science+Business Media Inc., ISBN 0-7923-7270-0.

[16] L. H. S. Barreto, J. B. Vieira Jr., E. A. A. Coelho, V. J. Farias, L. C. de Freitas, "The Bang-Bang Hysteresis Current Waveshaping Control Technique Used to Implement a High Power Factor Power Supply", IEEE Transactions on Power Electronics vol. 19, no. 1, pp. 160-168, Jan. 2004.

[17] L. C. de Freitas, et al. "A lossless Commutation PWM Boost Converter with unity Power Factor Operation", in Proc. of IEE European Conference on Power Electronics and Applications, pp.4454-4458, Sept. 1997. 